v. 1 ,

n.

3, p. 210-216,

dez.

1994

\title{
PROJETO DE PRODUTOS PARA SEREM FABRICADOS EM SÉRIE
}

\author{
Nilton Nunes Toledo \\ Professor Doutor do Departamento de Engenharia de Produção da Escola Politécnica da USP
}

Este trabalho caracteriza projetos de produtos para serem fabricados em série. Estabelece as premissas, os dados necessários e os pontos importantes em torno dos quais se deve trabalhar. Determina, em linhas gerais, as condições de lançamento de um produto de consumo. Relata experiência num projeto moderno. Especifica os resultados a serem alcançados no desenvolvimento de produtos a serem fabricados em série.

Palavras chaves: projeto do produto, projeto para manufatura e montagem, engenharia de processos, lançamento de produtos, qualidade de produtos, vida do produto.

\section{Introdução}

A grande diferença entre um projeto convencional de engenharia e o projeto de produtos para serem fabricados em série reside no fato de que estes devem satisfazer a um grande número de pessoas, induzindo-as a adquiri-los, e não servir, apenas, ao atendimento de uma encomenda bem especificada, como a de uma máquina, a de uma instalação ou de uma edificação.

O fato de ser um produto projetado para ser fabricado em série pressupõe que será produzido um grande número de unidades. Portanto, a economia de até um grama de matéria prima por unidade se torna muito importante. No caso do projeto de uma máquina, por exemplo, o esforço de otimização em tais níveis não seria econômico, tendo em vista o pequeno número de unidades a serem produzidas. .

A vida do produto tem que ser previamente conhecida, para que se possa oferecer as garantias que o consumidor necessita. Isto requer uma série de ensaios de resistência, desempenho e funcionalidade, antes do lançamento do produto. É portanto, necessário que:

-a quantidade a ser fabricada seja corretamente estimada, pois ela contribui para a definição do processo mais adequado e da respectiva matéria prima a ser usada; 
-cada componente do produto suporte o número previsto de horas de vida, para garantir sua confiabilidade, o que não comporta nenhuma improvisação;

-os custos unitários de fabricação, que são também função do processo, sejam conhecidos a priori, como uma estimativa prévia, a cada evolução do desenvolvimento, pois qualquer indício de custos mais altos do que os preços do mercado deve desencadear revisões e até desistências;

-a fábrica seja dimensionada ou adaptada para se ter a melhor produtividade,em função das quantidades estimadas;

-os profissionais da área de Marketing e da Engenharia de Produto tenham interpretado adequadamente a reação do mercado, face às últimas tendências da moda, a consultas diretas ou a lançamentos experimentais (reática). Assim, com base no plano estratégico da empresa, irão definir produtos a serem lançados, com suas quantidades e respectivos preços.

\section{Lançamento, Desenvolvimento e Evolução de um Novo Produto}

A decisão de lançamento de um produto é normalmente uma decisão estratégica, porque toda empresa se instala para explorar áreas de mercado bem específicas, especializando-se na interpretação dos desejos do consumidor deste mercado e no seu canal de distribuição. Sendo o Marketing o executor do plano estratégico de linha de produtos, esta decisão deve partir da área de Marketing das empresas, porém fundamentada em dados econômicos e financeiros:

-econômicos, porque a comercialização do produto deve gerar lucro capaz de pagar os custos envolvidos na operação contínua e também o investimento no desenvolvimento do produto, no ferramental necessário, na propaganda inicial de lançamento e no acréscimo de capital de giro, no entanto, sabe-se que para atender às necessidades estratégicas da empresa, é possível lançar produtos que não propiciem retorno imediato, mas apenas a complementação de uma linha ou o encaminhamento de negócios para outros produtos, justificando-se assim a ausência de lucro neste item.

-financeiros, porque a empresa deve dispor do montante de dinheiro necessário, em caixa ou em forma de financiamento.

Devemos lembrar que existem também condições especiais que impõem o lançamento de produtos. Por exemplo: - o setor de Pesquisa e Desenvolvimento chegou a um produto inédito que, por isso, deve ser testado no mercado; - a vocação industrial da empresa em determinadas tecnologias de fabricação lhe dá vantagens competitivas e ganho de escala, para produtos compatíveis com estas tecnologias.

Embora a decisão seja estratégica, é necessário obter todos os dados do produto, o que é problemático, considerando que ele ainda não está completamente definido, e muito menos os processos de fabricação, bem como os investimentos a serem realizados.

O processo de coleta de dados tem sido, tradicionalmente, interativo: as primeiras informações, muito pobres, usam-se para as decisões preliminares de continuar os estudos ou desistir. À medida que se conhece mais a respeito do problema, novas e mais importantes decisões são tomadas, na seguinte seqüência: 
-do plano estratégico de linha de produtos, para a idéia de produto;

-da idéia de produto para o mercado;

-do mercado para o Marketing;

-do Marketing para a Engenharia de Produto;

-da Engenharia de Produto para a Engenharia de Processos.

Nesse ponto propõe-se uma solução prévia, com dados de custos do produto e investimentos ainda estimados e com grande margem de erro. Esses dados, considerados em conjunto com os dados de mercado: quantidade e preço. Com a comparação entre preço e custo, pode-se chegar à decisão de prosseguir ou interromper o processo, ou seja: se os preços que o mercado aceita pagar estiverem muito acima dos custos do produto, continua-se. Se estiverem próximos, deve-se estudar simplificações, melhorias, novas soluções que recaiam no caso anterior. Se os custos estiverem muito acima dos preços, não sendo viável o lançamento do produto neste momento, deve-se guardar a idéia para uma próxima oportunidade, ou lançá-lo com prejuízo, em face do planejamento estratégico da empresa.

Como se pode imaginar, o procedimento acima deve repetir-se várias vezes, à medida que o projeto evolui e a precisão dos dados vai melhorando.

Este procedimento nem sempre é seguido, ainda hoje, por falta de conhecimento, ou por outras razões. Tradicionalmente, a decisão de lançamento de produtos é tomada de maneira pouco formal, geralmente imposta por uma área da empresa que, tendo maior influência sobre o poder concedente , faz prevalecerem suas idéias.

Pode-se citar, por exemplo, a área de Processos, procurando impor a forma do produto e materiais que aproveitem os processos instalados. Insistiria em manter, por exemplo, peças metálicas, de custo mais alto que o de peças de plástico de desempenho semelhante, justificando esta decisão com a afirmação: "nosso negócio é peça metálica", quando na realidade o "negócio" está relacionado com o produto e seu mercado e não com o processo de fabricação e seus materiais. Forçar o uso de peças existentes, com padrões anteriormente estabelecidos, pode ser uma solução barata, desde que possível, mas pode comprometer o desempenho do produto no mercado, se este considerar as peças aproveitadas como sendo de baixa qualidade.

Outro exemplo seria a área de Engenharia de Produto, procurando inovar e aperfeiçoar constantemente o produto, sempre achando que "não está bom" e que "é preciso melhorar". Freqüentemente propõe formas e materiais, sem a preocupação de verificar como se comportarão no processo, preocupando-se apenas com o seu comportamento no desempenho do produto e na simplificação deste. Não é suficiente desenhar um produto ou uma peça que o compõe, pensando só no seu desempenho: ela precisa ser fabricável. Para ter certeza de que a peça vai funcionar bem no produto, devemos construir um modelo e colocá-lo à prova. Geralmente são necessárias modificações sucessivas, até que a peça e o produto funcionem bem - só assim poderemos dar por terminado o projeto da peç, para então, iniciar o projeto do processo.

Como nos exemplos dados, pode-se verificar que as diversas áreas de atividade envolvidas no projeto do produto têm enfoques diferentes e cada uma considera o seu, 
o mais importante. É claro que todas as áreas são igualmente importantes e cada uma deve contribuir com sua parte, porém, em um trabalho integrado.

Tradicionalmente esses profissionais estão dedicados às rotinas do dia-a-dia e nem sempre conseguem tempo para discutir a inovação. O que se busca atualmente é estabelecer uma forma de trabalho que concilie todos os interesses em jogo no projeto, de maneira a obter-se: "um produto que agrade o consumidor, apresente a melhor qualidade, seja fabricado pelo menor custo e possa ser realizado no menor tempo possível, com o menor investimento".

Esta forma de trabalho é hoje chamada "Engenharia Simultânea". Para o seu funcionamento, é nomeado um Coordenador com plenos poderes para promover, dentro da empresa, a tomada de decisões consensuais e simultâneas em todas as áreas.

As decisões tomadas pelo grupo de Engenharia Simultânea vão gerar uma série de atividades que dão continuidade ao desenvolvimento do produto. Uma das mais importantes é o dimensionamento dos componentes deste produto: usar todas as técnicas da engenharia não é suficiente; o que torna o projeto eficiente é testar de alguma forma, na prática, o que foi calculado no modelo teórico. Repetindo o que já foi dito: é necessário construir um modelo físico ou um modelo de simulação em computador, para ensaiar suas funções, sua vida e sua aceitação no mercado.

Como ilustração da etapa de dimensionamento de um componente do produto, será descrita a seguir, uma experiência vivida pelo autor desse trabalho.

\section{Relato de Experiência na Indústria de Plástico}

Os recursos para o projeto de peças de plástico têm evoluído muito e hoje se pode testar, em computador, a forma das peças a serem construídas com este material. Os testes se referem à espessura de paredes, nervuras e qualquer singularidade que seja necessária na peça. Tudo isso para que se consiga um bom desempenho do processo de fabricação. Atinge-se, assim, o desejado estágio de custo mínimo, no que se refere a quantidade de material e ciclo de operação.

A forma da peça deve ser projetada para que ela atenda às necessidades do produto. Portanto, a sua resistência é calculada usando-se as técnicas da engenharia. A próxima etapa é projetar o processo de fabricação e é aí que são usados os recursos referidos.

O procedimento a ser seguido parte do projeto da peça que compõe o produto em desenvolvimento. Este projeto já é concebido para uma peça a ser fabricada em plástico; a decisão quanto ao plástico a ser usado deve ser tomada levando-se em consideração as condições de trabalho da peça, isto é: esforços mecânicos, temperaturas, pressões, iluminação, agentes químicos, etc. Sabendo-se que plástico usar, desenha-se a peça, dimensionando cada secção de sua estrutura, sujeita a esforços. Com esse desenho, constrói-se a peça artesanalmente, de preferência com o próprio plástico escolhido, ensaiando-a quanto à montagem, no protótipo do produto.

Se possível, submete-se o produto ao funcionamento, para testar a peça: se funcionar bem, estará aprovada; se não, terá que ser modificada. Esta operação se repetirá até conseguir-se a aprovação da peça. 
Após sua aprovação, deve-se dimensioná-la para otimizar o seu processo de fabricação, com o procedimento a seguir:

-com um software chamado "Mold Flow", coloca-se o desenho da peça no computador; o projetista esquematiza o molde, projeta os seus canais de alimentação, localizando-os na peça como sua experiência melhor indicar.

O programa vai agora simular o preenchimento da peça, em várias condições de trabalho, mostrando para cada uma delas o resultado, isto é, como o preenchimento da peça se deu, as temperaturas em cada ponto, o estado de tensões em cada ponto, os possíveis empenamentos, as linhas de fluxo resultantes, os vazios e porosidades característicos do fim de fluxo de injeção e o tempo provável de operação.

O projetista verifica se o resultado é aceitável; se não for, ele deve mudar o ponto de injeção e repetir os ensaios. A cada repetição, ele vai tirando conclusões sobre a peça e pode modificá-la, para melhorar o desempenho do processo, mudando espessura de paredes, introduzindo nervuras que funcionem como diretores de fluxo, saídas de ar da cavidade, etc. Depois de um número finito de interações, chega-se aos parâmetros básicos para o projeto do molde, tais como: forma da peça; forma e dimensões dos canais e seu ponto de alimentação; distribuição de pressões e de temperaturas.

Até esse ponto, projetou-se a peça para ser construída com um determinado material. O projeto do molde pode também ser executado no computador, usando-se um soft adequado para desenho técnico, sendo agora necessário um software especial para o projeto do sistema de refrigeração, o "Mold Cold", com o qual o projetista, similarmente ao trabalho com o "Mold Flow", vai projetar o sistema de refrigeração do molde, conforme sua experiência. Ele desenha a tubulação que será construída no molde, baseado na distribuição de temperaturas obtida na fase anterior; faz rodar no computador a primeira versão de sistema de refrigeração; ainda em um processo interativo, mudando e simulando as trocas de calor, chegará a uma tubulação de refrigeração, que resultará numa distribuição de temperaturas ideal para o processo de injeção. É importante saber que devido à importância do sistema de refrigeração do molde, ele deve ser projetado antes, garantindo assim espaço necessário à tubulação de refrigeração. Após isso, projeta-se o sistema de extração, estrutura do molde, etc.

O processo não termina aí, pois todo esse aparato descrito não passa de uma simulação, um modelo, sendo necessário construir o molde, colocá-lo em máquina, injetar peças para saber se tudo está certo ou se tudo se dá conforme o esperado. Raramente acontece estar tudo de acordo; é sempre necessário modificar alguma coisa ou quase tudo. A grande diferença de se ter usado um sistema CAD, CAE é que se vai chegar à solução do problema muito mais rapidamente, evitando-se uma série de modificações no estágio de molde pronto, que é mais caro que aquelas feitas em simulação no computador. Não é desejável, nem prático, realizar mudanças no molde pronto; o ideal é que ele funcione conforme esperado, que a peça obtida seja usável. Para que aconteça isso, temos que contar com a habilidade do projetista, que precisa de grande experiência e conhecimento teórico, além de saber usar corretamente todos os recursos dos softs. 


\section{Conclusão}

O que se pode concluir é que o projeto de um componente de um produto (peça) não vai ser feito em uma primeira tentativa - é necessário percorrer toda uma série de etapas: desenhos preliminares, construção de modelos, ensaios do produto no mercado, definição das quantidades, definição dos processos, reprojeto da peça (adaptação ao processo), especificações dos materiais, construção de modelos teóricos e físicos, ensaios do processo para a peça, reprojeto da peça, delineamento de experimentos para os ensaios do produto, ensaios da peça no produto, análise das ocorrências, novas modificações, assim sucessivamente, até chegar a uma peça que funcione e seja economicamente fabricável. Finalmente, executam-se os desenhos definitivos.

Este é o procedimento denominado "desenvolvimento do produto", onde o conhecimento do pessoal envolvido sobre a peça/processo evolui a cada etapa, permitindo o seu aperfeiçoamento (lembrando mais uma vez, que todos esses cuidados se justificam, porque o projeto de produtos para serem fabricados em série,geralmente pressupõe a fabricaçãao de grandes quantidades).

Podemos afirmar, então, que modernamente, num projeto de produtos para serem fabricados em série, os seguintes aspectos são fundamentais:

1-As quantidades de produtos a serem fabricados definem os processos de fabricação que são mais adequados;

2-É necessário encontrar, entre os processos adequados, um que seja economicamente viável, isto é, que produza peças de custos mais baixos que os preços encontrados no mercado, para estas quantidades e que não polua o ambiente;

3-Deve ser possível a construção de modelos que possam representar fielmente o produto e que possam ser ensaiados em todas as condições de uso, por tempos que sejam iguais à vida esperada do produto. Esta é condição "sine qua non", no procedimento proposto;

4-Só se poderá ter os desenhos definitivos das peças que compõem o produto, após os ensaios e aprovação dos protótipos, realizados com o ferramental definitivo;

5-Os projetos serão executados com a prática da "Engenharia Simultânea", que consiste em "projetar produtos para fabricação", por intermédio de uma equipe multidisciplinar, isto é, que tenha um ou mais representantes de cada área de atividade, coordenada por um responsável de alto nível hierárquico;

6-A qualidade dos produtos deverá nascer com a correta escolha do equipamento que irá fabricar as suas peças, ou seja, adequando a fábrica aos produtos.

7-A qualidade dos produtos deverá ser definida de acordo com as necessidades do consumidor, observando-se os seguintes pontos:

-desempenho, compreendendo a vida e confiabilidade;

-funcionalidade, compreendendo características especiais, qualidade de uso;

-forma, compreendendo a estética, o toque;

-pós-venda, compreendendo o atendimento nas instruções de uso, manutenção;

8-O produto não deve poluir o ambiente, quer com o uso, quer após ser descartado no fim da sua vida. 
v. 1 ,

n. 3

3, p.

210-216,

dez.

1994

\section{Bibliografia:}

CLARK, B.K. \& FUGIMOTO: Product development performance. Harvard Busines School Press, Boston, 1991.

EUREKA, E. W. \& RYAN, E. N.: The costumer driven company. A S I Press, Deaborn, 1988.

HAYES, R. \& WHEELWRIGT, S. C.: "Link manufacturing process and product life cycles". Harvard Business Review, p.133-140, jan./fev.1979.

STOLL, HENRY D.: "Design for manufacturing". Manufacturing Engineering, p.67-73, jan. 1988.

TOLEDO, NILTON NUNES: Metodologia para o Desenvolvimento de Produtos para Serem Fabricados em Série, Tese de Doutoramento, Escola Politécnica da USP, São Paulo, 1994

\section{THE DESIGN OF PRODUCTS TO BE MANUFACTURED IN SERIES}

ABSTRACT - This paper caracterizes the series manufacture products design It puts the premisses and the most important requirement data for this activiy. Here we have the general conditions required to introduct a product on the market. It presents also an experience in modern industry design. To finish, it especifies the results to be reached in the series manufacture products design.

Key words: Product Design, Design for Manufacture and Assemble, Process Engineering, Product Engineering, Product's Quality, Product's Life 